\title{
CARACTERIZAÇÃO ECONÔMICA E SOCIAL DOS PESCADORES DO RIO TOCANTINS EM MARABÁ - PARÁ
}

\author{
Gustavo Ferreira de Oliveira ${ }^{1}$; Sandro Ferreira Nascimento ${ }^{2}$; Andréa Hentz de Mello ${ }^{3}$; \\ Verônica Danielle Nascimento Pereira ${ }^{4}$; Aila da Silva Mendes ${ }^{5}$ \\ ${ }^{1}$ Discente de Agronomia da Faculdade de Ciências Agrárias de Marabá, Universidade Federal do Pará, Bolsista Pibex- \\ Água, gf.oliveira90@ hotmail.com \\ ${ }^{2}$ Discente de Agronomia da Faculdade de Ciências Agrárias de Marabá, Universidade Federal do Pará, Bolsista Pibex- \\ Água, sandro-fn@hotmail.com \\ ${ }^{3}$ Professora Adjunta II da Faculdade de Ciências Agrárias de Marabá , Universidade Federal do Pará, \\ andreahentz@ufpa.br \\ ${ }^{4}$ Discente de Agronomia da Faculdade de Ciências Agrárias de Marabá, vdanille@ hotmail.com \\ ${ }^{5}$ Discente de Agronomia da Faculdade de Ciências Agrárias de Marabá,aillamendes@ @otmail.com
}

RESUMO: A caracterização do perfil sócio-econômico dos pescadores do Rio Tocantins em Marabá torna - se importante para subsidiar futuras intervenções. O objetivo deste trabalho foi apresentar o perfil sócio-econômico dos pescadores de Marabá - PA. Para tanto, foram realizados questionários semi - estruturados aplicados nas principais comunidades de pescadores moradores à margem esquerda do Rio Tocantins. Os resultados foram comparados a partir de outros estudos realizados em 2007, tais como a faixa etária da população, origem do grupo familiar, ocupação, condições de saneamento, noções sobre a qualidade da água, origem da água para consumo e vários outros aspectos que se mostram pertinentes para a construção de um perfil socioeconômico da comunidade que habita a beira do Rio Tocantins em Marabá e exercem a atividade da pesca como meio de sobrevivência.

PALAVRAS-CHAVE: comunidade, entrevistas, perfil sócio-econômico.

\section{SOCIAL AND ECONOMIC CHARACTERISTICS OF FISHERMEN IN RIVER TOCANTINS MARABÁ - PARA}

\begin{abstract}
The characterization of the socio-economic profile of fishermen from the Tocantins River in Maraba it-is important to support future operations. The objective was to present the socioeconomic profile of fishermen in Maraba- PA. Thus, we performed semi - structured used in major fishing communities living on the left bank of Rio Tocantins. The results were compared from other studies conducted in 2007, such as age group origin of the family, occupation, sanitation notions various other aspects that appear to be relevant for the construction of a socioeconomic profile of the community that inhabits the banks of the Rio Tocantins in Maraba and exert the activity the of fishing as a livelihood.
\end{abstract}

KEY-WORDS: community, interviews socio-economic profile.

\section{INTRODUÇÃO}

A disponibilidade de água doce no planeta foi no século passado objeto de diversos temas e legislação debatida em fóruns internacionais e nacionais, dos quais resultaram convenções onde se contemplou a prevenção e a pesquisa como parte de uma política ambiental na esfera mundial. Assim, é importante lembrar que "a água não é somente uma herança de nossos 
predecessores, ela é, sobretudo, um empréstimo aos nossos sucessores. Sua proteção constitui uma necessidade vital, assim como uma obrigação moral do homem para com as gerações presentes e futuras" (DECLARAÇÃO UNIVERSAL DOS DIREITOS DA ÁGUA - ART. 5º 1992).

O Rio Tocantins obteve importante papel na ocupação de Marabá, devido à atração pela possibilidade de exploração econômica extrativista. Porém devido às sucessivas intervenções humanas tanto a qualidade da água como as suas quantidades estão sendo alteradas, refletindo assim na disponibilidade do pescado na região.

A pesca é uma das atividades extrativistas mais tradicionais e importantes da Amazônia, sendo muito praticada pela comunidade ribeirinha do Rio Tocantins, caracterizando-se por diferentes tipos de usuários dos recursos pesqueiros, com diferentes estratégias de pesca e diferentes comportamentos frente aos recursos e ao ambiente (FREITAS; RIVAS, 2006). Em Marabá a atividade pesqueira faz parte de sua história sendo uma das principais atividades de subsistência da população nos primórdios do município (BORGO, 2007).

Assim, este trabalho teve o objetivo de caracterizar o perfil econômico e social dos pescadores ribeirinhos da Orla do Rio Tocantins em Marabá, com o intuito de conhecer melhor esta categoria social tão carente e servir como instrumento para futuras intervenções.

\section{MATERIAL E MÉTODOS}

Este trabalho foi realizado na Orla do Rio Tocantins, na cidade de Marabá no período de março de 2010 a janeiro de 2011. A amostragem foi composta por 58 famílias entre aquelas que moravam entre 10 a 300 m de distância das margens do Rio Tocantins. As entrevistas foram distribuídas nos bairros Santa Rosa com 35 entrevistados, na Rua Marechal Deodoro e Avenida Pará, Francisco Coelho (Cabelo Seco) 20 entrevistados ao longo da Rua Quintino Bocaiúvas e no Santa Rita três entrevistados na Rua das Mangueiras ambos dispostos ao longo da orla urbana da cidade de Marabá.

A maior parte dos questionários aplicados foram no bairro Santa Rosa pelo fato de ter o maior número de famílias de pescadores que são moradoras nas margens do rio. Nesse bairro foram entrevistados 35 moradores que equivalem a $60,34 \%$ dos entrevistados. O bairro Francisco Coelho foi escolhido também por lá estarem os pescadores mais antigos da cidade. Nesse bairro foram entrevistados 20 pescadores que habitavam as margens do Rio Tocantins, o que equivale a $34,48 \%$ das entrevistas. $\mathrm{O}$ bairro Santa Rita é o mais recente entre os bairros estudados nesse trabalho. Nesse bairro foram entrevistados três pescadores, o que representa uma amostra de 5,18\%. O levantamento socioeconômico foi realizado através da aplicação de questionários a partir de estudos realizados por Borgo (2007) para a obtenção de informações sobre os atores 
sociais (comunidades de pescadores moradores da beira do rio), bem como o modo de vida destes habitantes das margens do rio Tocantins em Marabá - PA. As informações coletadas referiram - se sobre a faixa etária da população, origem do grupo familiar, ocupação, condições de saneamento, noções sobre a qualidade da água, origem da água para consumo e vários outros aspectos que se mostram pertinentes para a construção de um perfil socioeconômico da comunidade que habita as margens do rio Tocantins em Marabá e exercem a atividade da pesca como meio de sobrevivência. Os dados coletados com a aplicação de questionário foram processados no aplicativo Microsoft Excel, 2007.

\section{RESULTADOS E DISCUSSÃO}

PERFIL SOCIOECONÔMICO DOS PESCADORES DE MARABÁ

Com relação à idade dos entrevistados (Tabela 1) nota-se que considerando a faixa etária mínima de 20 anos a 76 anos, a maior concentração populacional (33\%) corresponde às pessoas na faixa etária entre 28 a 36 anos, sendo que $28 \%$ têm entre 36 a 44 anos e 11 $\%$ têm entre 44 a 52 anos. O que mostra que a maioria dos pescadores é composta por adultos o qual evidencia pouca alteração no trabalho realizado por Borgo (2007). A caracterização dos entrevistados é importante para que futuras intervenções possam considerar o homem como parte integrante do meio.

Tabela 1: Faixa etária dos Pescadores de Marabá-PA. (Dados da pesquisa)

\begin{tabular}{lcc}
\hline IDADE & NÚMERO DE PESCADORES & $\%$ \\
\hline 20 a 28 & 4 & 7 \\
28 a 36 & 19 & 33 \\
36 á 44 & 16 & 28 \\
44 a 52 & 7 & 11 \\
52 a 60 & 6 & 10 \\
60 a 68 & 5 & 9 \\
68 a 76 & 1 & 2 \\
Total & 58 & 100 \\
\hline
\end{tabular}

A escolha da profissão de pescador (Figura 1) é apontada pela maioria dos entrevistados como uma forma de sobrevivência (58\%), seguida da tradição familiar (28\%), dados estes que não corroboram com os de Borgo (2007), que obteve a tradição familiar como principal responsável pela escolha da profissão de pescador.

Agroecossistemas, v. 3, n. 1, p. 18-23, 2011 


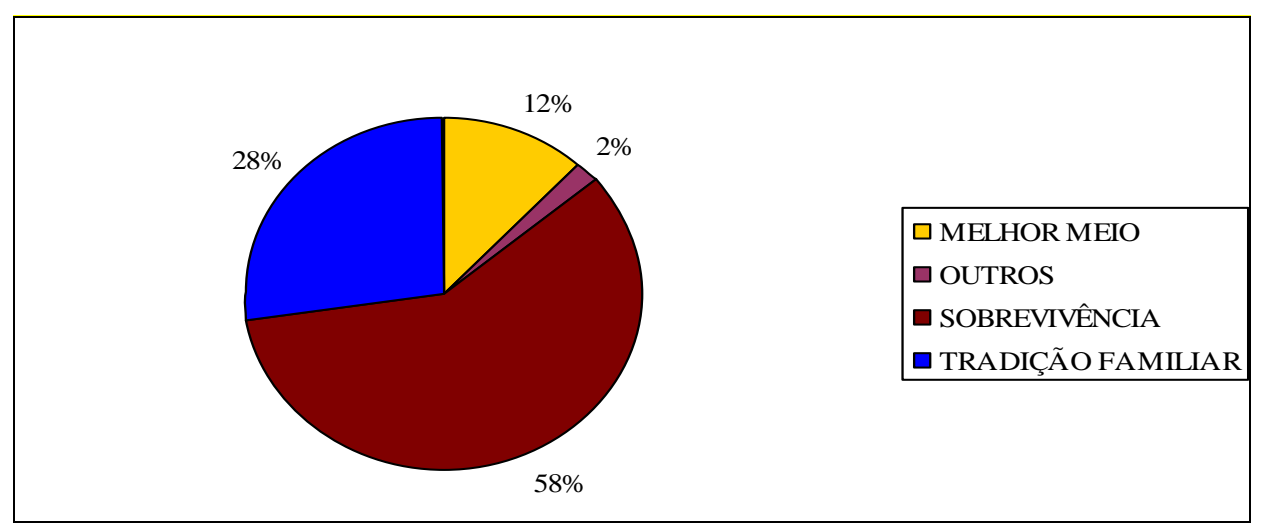

Figura 1. Motivo da escolha da profissão dos pescadores de Marabá - PA. (Dados da pesquisa)

Entre os entrevistados $78 \%$ dos pescadores possui casa própria, isso pelo fato de que os pescadores tiveram estabilidade financeira nesta atividade, apesar de o ganho salarial ser variáveis, conseguiram comprar a casa e outros bens. É o que é demonstrado na Tabela 2, a respeito das condições de residência dos pescadores.

Tabela 2: Condição de residência dos Pescadores de Marabá-PA. (Dados da pesquisa).

\begin{tabular}{lcc}
\hline RESIDÊNCIA & $\mathrm{N}$ & $\%$ \\
\hline ALUGADA & 8 & 14 \\
DOS PAIS & 2 & 3 \\
OUTROS & 3 & 5 \\
PRÓPRIA & 45 & 78 \\
TOTAL & 58 & 100 \\
\hline
\end{tabular}

Quanto à naturalidade dos pescadores, a pesquisa revelou que $48 \%$ dos entrevistados nasceram em Marabá, contra $52 \%$ que vieram de outras localidades. A maior parte dos imigrantes é do Estado do Maranhão, representando $20 \%$ do total, seguido dos imigrantes de outras cidades do Pará e de famílias que vieram no Rio Grande do Norte. Comprovando o estudo de (BORGO, 2007) o qual mostra que a maioria dos pescadores é de outras localidades (Tabela 3 ). 
Tabela 3: Origem dos Pescadores entrevistados no núcleo urbano de Marabá - PA. (Dados da Pesquisa).

\begin{tabular}{lcc}
\hline ORIGEM DOS PESCADORES ENTREVISTADOS & QUANTIDADES DE VEZES CITADAS & $\%$ \\
\hline CEARÁ & 1 & $2 \%$ \\
GOIÁS & 1 & $2 \%$ \\
MARABÁ - PA & 28 & $48 \%$ \\
MARANHÃO & 12 & $20 \%$ \\
MINAS GERAIS & 1 & $2 \%$ \\
PALESTINA - PA & 1 & $2 \%$ \\
PARAÍBA & 1 & $2 \%$ \\
PERNAMBUCO & 1 & $2 \%$ \\
PIAUÍ & 3 & $5 \%$ \\
RIO GRANDE DO NORTE & 4 & $6 \%$ \\
SÃO JOÃO DO ARAGUAIA - PA & 1 & $2 \%$ \\
TOCANTINS & 3 & $5 \%$ \\
TUCURUÍ - PA & 1 & $2 \%$ \\
TOTAL & 58 & $100 \%$ \\
\hline
\end{tabular}

No Bairro Santa Rosa, foi analisado o entendimento dos moradores em relação à qualidade das águas do Rio Tocantins, e os dados questionados foram se a qualidade da água era boa ou ruim, o qual comprova os dados do trabalho de Borgo (2007) no qual a maioria questiona a qualidade da água do Rio Tocantins em Marabá-PA como mostra a Figura 2.

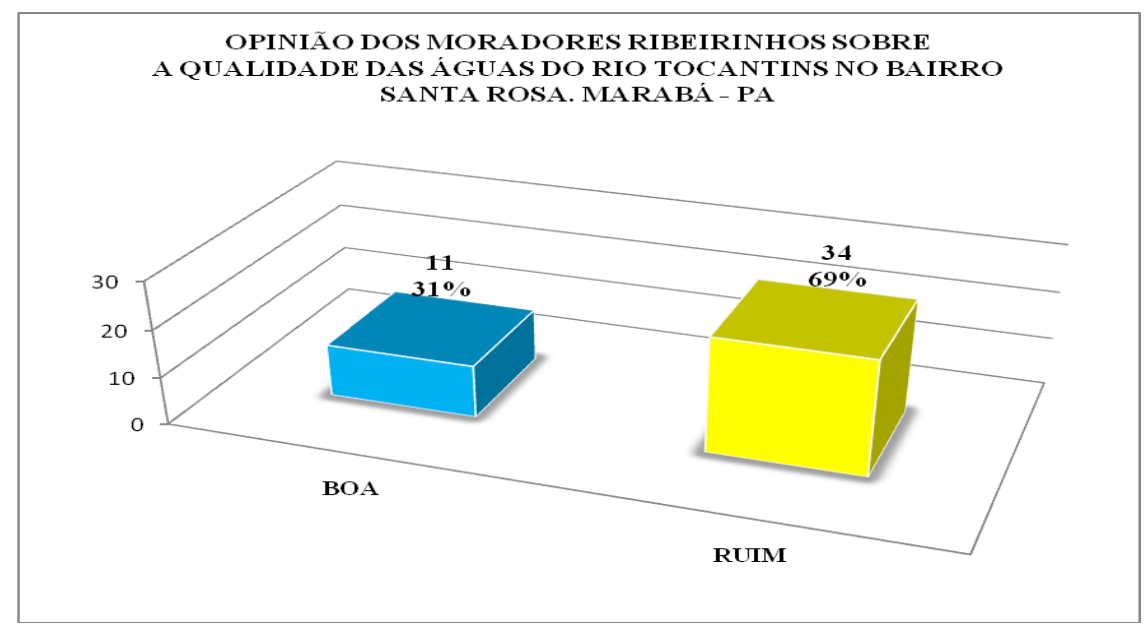

Figura 2: Opinião dos moradores ribeirinhos sobre a qualidade das águas do rio Tocantins no Bairro Santa Rosa. Marabá - PA. (Dados de pesquisa). 


\section{CONCLUSÃO}

A caracterização do perfil sócioeconômico dos pescadores em Marabá-PA torna-se muito importante para analise de questões por qual passa essa classe, levantando e mostrando problemas que são pertencentes nas comunidades ribeirinhas e o mais importante a relação que os moradores têm sobre a qualidade e conservação evidenciando o papel e a importância da sustentabilidade do Rio Tocantins para Marabá.

\section{REFERÊNCIAS}

BORGO, J. D. H. Água e sociedade: diagnóstico do uso socioeconômico e ambiental do rio Tocantins em Marabá PA. 2007143 f. Trabalho de Conclusão de Curso (Bacharelado em Agronomia) Faculdade de Ciências Agrárias, Universidade Federal do Pará, Marabá, 2008.
DECLARAÇÃO UNIVERSAL DOS DIREITOS DA ÁGUA - ART. 5º 1992.

FREITAS, C. E. de C.; RIVAS, A. A. F. A pesca e os recursos pesqueiros na Amazônia Ocidental. Cienc. Cult., São Paulo, v. 58, n. 3, 2006. 